\title{
DECISION MAKING IN WATER RESOURCES WITH FUZZY INFORMATION
}

\section{TZIMOPOULOS \\ C. EVANGELIDES*}

\author{
Aristotle University of Thessaloniki \\ Thessaloniki Department of Rural and Surveing Engineering
}

Thessaloniki, Greece
Received: $24 / 03 / 10$

Accepted: 04/10/11 *to whom all correspondence should be addressed: e-mail: evan@vergina.eng.auth.gr

\section{ABSTRACT}

The multiple objectives optimization in water resources planning consists in trading multiple and conflicting objectives, forming a complex and dynamic process. In the last four decades multiobjective decisions based on fuzzy sets have been evolved and considerable research spawned into the application of fuzzy subsets. Multiobjective decisions problems with uncertainty require: a) evaluating how well each alternative or choice satisfies each objective and b) combining the objectives into an overall objective or decision function $D$ for the selection of the best alternative. In particular when one has a) a universe of $n$ alternatives $X=\left\{X_{1}, X_{2}, \ldots X_{n}\right\}$ and a set of $p$ objectives (criteria) $A=\left\{A_{1}, A_{2}, \ldots . A_{p}\right\}$ to be satisfied, the overall objective is $D=A_{1}$ and $A_{2} \ldots \ldots$...and $A_{p}$, given by the intersection of all the objectives, $D=A_{1} \cap A_{2} \ldots . . \cap A_{p}$ and one is seeking solutions satisfying $D$, with $\mu_{D}\left(X^{*}\right)=\max \left(\mu_{D}(X)\right)$, where $\mu_{D}(X)$ is the grade of membership that the decision function $D$ has for each alternative. An application of the above theory concerns the decision of selecting the most appropriate from five dams and their corresponding reservoirs in Néstos watershed (Alternatives $A B$, $A D, A R, B A$, and $M A)$. The criteria set is $A=\left\{A_{1}=\right.$ cost of the dam, $A_{2}=$ environmental impact, $A_{3}=$ Hydroelectric power production, $A_{4}=$ flood protection) and finally the importance set is: $P=\left\{b_{1}, b_{2}\right.$, $\left.b_{3}, b_{4}\right\}$.

KEYWORDS: multiple objectives optimization, fuzzy analysis, membership function, Néstos reservoirs, preferences(importance)

\section{INTRODUCTION}

Most problems of today's concern are characterized by multiple objectives, criteria or goals according to which the best solution is to be found. Because of the conflicting character and noncommensurability of such criteria, a concept of multiple objective satisficing rather than optimal solution is more useful for their analysis (Zeleny, 1982). A water resources problem belongs to this category and especially today the decrease of available water resources and the degradation of water quality as well as the rapid increase of population combined with the growth of human activities, have forced engineers to contemplate and propose even more comprehensive, complex, and ambitious plans for water resources systems. The application of systems methods such as mathematical optimization and simulation can satisfactory aid to the definition, evaluation and selection of water resources investments, design and policies.

Water resources planning must take into account multiple users, multiple purposes, and multiple objectives. Water engineers and planners should develop a number of reasonable alternatives for public officials to consider. They should also evaluate the economic, environmental, political and social impacts that might result from each alternative. So it is impossible to develop a single objective that satisfies all interests, all adversaries, and all political and social viewpoints (Loucks et al., 1981; lliadis and Maris , 2007).

Multiobjective or multicriterion optimization in water resources planning consists in trading multiple and conflicting objectives, forming a complex and dynamic process (Zeleny, 1982). A water resources problem may have various design levels, from a simple structure to the construction of a 
complex system with managerial and engineering elements. For the design of a complex structure (for example a surface reservoir) a variety of natural phenomena are incorporated in the design and increase the conflicting objectives. Many methods have been evolved for the evaluation of the above problems: ELECTRE I (Roy, 1968), AHP (Saaty, 1975; 1977; 1980), ELECTRE II and ELECTRE III (Belton and Stewart, 2001), Compromise Programming (Zeleny, 1982), MCQA-I and MCQA-II (Duckstein et al., 1991).

As decision sciences become more and more involved in both humanistic and complex systems, fuzziness becomes a prevalent phenomenon in describing these systems. Zadeh (1973) calls these fuzziness as the "Principal of Incompatibility" : as the complexity of a system increases, our ability to make precise and yet significant statements about its behavior, diminishes until a threshold is reached beyond which precision and significance become almost mutually exclusive characteristics and finally the closer one looks at a real-world problem, the fuzzier becomes its solution. In the last four decades multi-objective decisions based on fuzzy sets have been evolved and considerable research spawned into the application of fuzzy subsets. (Belmann and Zadeh, 1970; Yager, 1975; 1977; 1978; 1981), Kecman, 2001; Ross, 2004; Cox, 2007; lliadis, 2007). Multiobjective decisions problems with fuzziness require the choice of one element from a set $\{X\}$ of possible alternatives, given a collection of criteria of concern to the decision maker. So two problems arise: a) evaluating how well each alternative or choice satisfies each objective and b) combining the objectives into an overall objective or decision function $D$ for the selection of the best alternative. In particular when one has a) a universe of $n$ alternatives $X=\left\{X_{1}, X_{2}, \ldots, X_{n}\right\}$ and a set of $p$ objectives (criteria) $A=\left\{A_{1}, A_{2}, \ldots . A_{p}\right\}$ to be satisfied, the overall objective is $D=A_{1}$ and $A_{2} \ldots \ldots$...and $A_{p}$, leading to the intersection of all the objectives, $D=A_{1} \cap A_{2} \ldots \ldots \cap A_{p}$ and one is seeking solutions satisfying $D$.

The maximizing decision $X^{*}$ will then be the alternative satisfying $\mu_{D}\left(X^{*}\right)=\max \left(\mu_{D}(X)\right)$, where $\mu_{D}(X)$ is the grade of membership that the decision function $D$ has for each alternative.

In this paper an application of the above theory concerning the decision of selecting one out of five dams (five alternatives) is presented, satisfying four objectives: a) The cost of the dam $\left.\left(A_{1}\right), b\right)$ the environmental impact of each dam $\left(A_{2}\right)$, c) the produced hydroelectric power $\left(A_{3}\right)$, and d) the protection of floods $\left(A_{4}\right)$. Additionally one also has to rank the preferences for these objectives on the unit interval $\left(b_{1}, b_{2}, b_{3}, b_{4}\right)$. The five dams (alternatives $A B, A D, A R, B A$, and $M A$ ) belong to the Néstos watershed in Greece.

\section{MATHEMATICAL MODEL}

\subsection{Preliminaries}

Fuzziness, as handled in fuzzy logic, can refer to various types of vagueness and uncertainty but particularly to the vagueness related to human linguistics and thinking, differing from the uncertainty of the Probabilistic Theory. In Boolean logic the boundaries of a set are clearly defined and it is evident whether an object belongs to a set or not. It is described by a binary function, the characteristic function, taking the value 0 when an element $x$ does not belong to the set $A$ and the value 1 when it does. On the contrary, in fuzzy logic, it is possible for elements to belong partially to a set (Zadeh, 1965).

\section{Definition 1. Fuzzy set}

If $X$ is a collection of objects denoted generically by $x$, then a fuzzy set $\tilde{A}$ on $X$ is a set of ordered pairs: $\tilde{\mathrm{A}}=\left\{\left(\mathrm{x}, \mu_{\tilde{\mathrm{A}}}(\mathrm{x})\right) \mid \quad \mathrm{x} \in \mathrm{X}\right\}, \quad \mu_{\tilde{\mathrm{A}}} \in[0,1]$, where $\mu_{\tilde{\mathrm{A}}}(\mathrm{x})$ is called the membership function or grade of membership (also degree of compatibility or degree of truth) of $x$ in $\tilde{A}$, that maps $X$ to the membership space $M$. When $M$ contains only two points 0 and $1, A$ is nonfuzzy and its membership function becomes identical with the characteristic function of a nonfuzzy set. The symbol $\sim$ will be referred to as a fuziffier (Zadeh, 1965).

\section{Definition 2. $\alpha$-level cut}

The (crisp) set of elements belonging to the fuzzy set $\tilde{\mathrm{A}}$ at least to the degree $\alpha$, is called the $\alpha$ level set, or the $\alpha$-cut : $A_{\alpha}=\left\{x \mid \mu_{A}(x) \geq \alpha\right\}$. If $A_{\alpha}^{\prime}=\left\{x \mid \mu_{A}(x)>\alpha\right\}$, it is called "strong $\alpha$ - cut". 


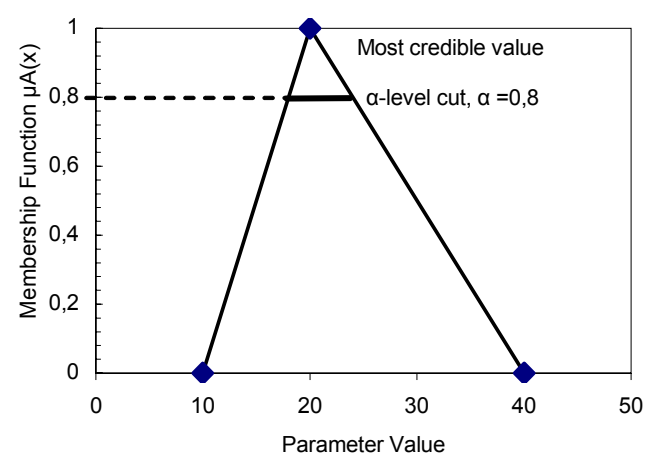

Figure 1. A fuzzy number and an $\alpha$ - cut

Definition 3. Convex fuzzy set

A fuzzy set is convex if:

$\mu_{\tilde{\mathrm{A}}}\left(\lambda \mathrm{x}_{1}+(1-\lambda) \mathrm{x}_{2}\right) \geq \mu_{\tilde{\mathrm{A}}}\left(\mathrm{x}_{1}\right) \wedge \mu_{\tilde{\mathrm{A}}}\left(\mathrm{x}_{2}\right), \mathrm{x}_{1}, \mathrm{x}_{2} \in \mathrm{X}, \lambda \in[0,1]$

Also, a fuzzy set can be convex if all $\alpha$-level sets are convex.

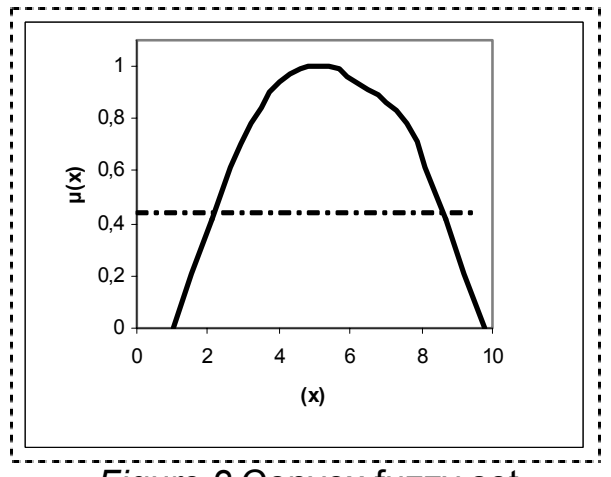

Figure 2.Convex fuzzy set

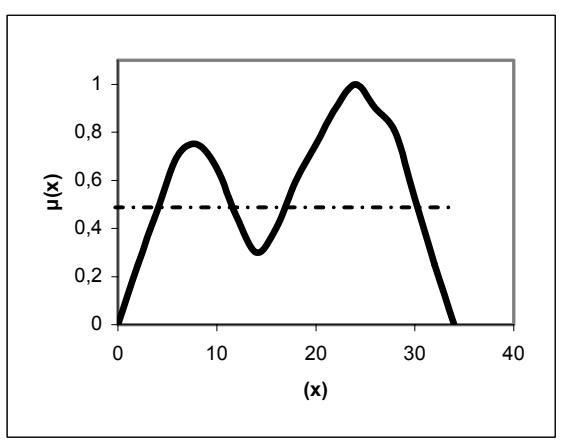

Figure 3. Nonconvex fuzzy set

Definition 4. Fuzzy numbers

A fuzzy number $\tilde{\mathrm{M}}$ is a convex normalized set $\tilde{\mathrm{M}}$ of the real line $\mathfrak{R}$ such that:

1. It exists exactly one $x_{0} \in \mathfrak{R}$ with $\mu_{\tilde{M}}\left(\mathrm{x}_{0}\right)=1$ ( $x_{0}$ is called the mean value of $\tilde{M}$ )

2. $\mu_{\tilde{M}}(\mathrm{x})=1$ is piecewise continuous.

Nowadays, this definition is very often modified. For the sake of computational efficiency, trapezoidal membership functions are often used. A triangular fuzzy number is, of course, a special case of this.

\section{Multiobjective decisions problems with uncertainty}

In the last four decades multi-objective decisions based on fuzzy sets have been evolved and considerable research spawned into the application of fuzzy subsets. Multiobjective decisions problems with uncertainty require the choice of one element from a set $\{X\}$ of possible alternatives, given a collection $\{A\}$ of criteria of concern to the decision maker. So two problems arise:

- Evaluating how well each alternative or choice satisfies each objective.

- Combining the objectives into an overall objective or decision function D, satisfying all the objectives, and from which we select the best alternative.

In particular when one has a collection $\{A\}=\left\{A_{1}, A_{2}, A_{3} \ldots \ldots . ., A_{p}\right\}$ of objectives to be satisfied, the overall objective is $D=A_{1}$ and $A_{2} \ldots \ldots$.and $A_{p}$, and one is seeking solutions satisfying $A_{1}$ and $A_{2}$ and $A_{3} \ldots$...tc. As the mathematical form for the "and" operation in fuzzy logic is the minimum operator (the intersection of fuzzy subsets) the decision function is:

$\mathrm{D}=\mathrm{A}_{1} \cap \mathrm{A}_{2} \cap \mathrm{A}_{3} \ldots \ldots \cap \mathrm{A}_{\mathrm{p}}$ 
and the corresponding membership function $\mu_{\mathrm{D}}$ :

$\mu_{\mathrm{D}}=\mu_{\mathrm{A}_{1}} \wedge \mu_{\mathrm{A}_{2}} \wedge \mu_{\mathrm{A}_{3}} \wedge \ldots \ldots \wedge \mu_{\mathrm{A}_{\mathrm{p}}}$.

Comment. It should be noted that Bellman and Zadeh (1970) identified the connective "and" with the conjunction symbol $\wedge$, interpreting "and" in a "hard" sense, that is, they do not allowed any tradeoffs between the memberships $\mu_{\mathrm{A}_{\mathrm{i}}}, \quad \mathrm{i}=1, \ldots . . \mathrm{p}$ (non-interactive "and"). In some cases a softer interpretation of "and" corresponds to forming the algebraic product of memberships $\mu_{A_{i}}, \quad i=1, \ldots . . p$ (Interactive "and"). From the mathematical as well as practical point of view, the identification of "and" with $\wedge$, is preferable to its identification with the product. The above operators (min and product) belong to a general class of operators for the intersection and union of fuzzy sets, called triangular norms (t-norms) and conorms (t-conorms or s-norms), (Zimmermann, 1996). Yager (1981) refers that the Bellman-Zadeh optimal solution leads always to a Pareto optimal solution and Ross (2004) refers it as optimum decision. In what follows "and" will be understood to be a hard "and", and the above expression becomes:

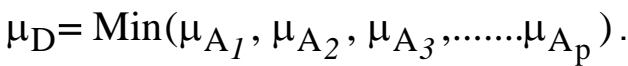

The optimal solution (Zimmermann, 1992; 1996; Ross, 2004) is Max $\left\{\mu_{D}\right\}$, that is:

$\operatorname{Max}\left\{\mu_{\mathrm{D}}\right\}=\operatorname{Max}\left\{\min \left(\mu_{\mathrm{A}_{1}}, \mu_{\mathrm{A}_{2}}, \mu_{\mathrm{A}_{3}}, \ldots \ldots . . \mu_{\mathrm{A}_{\mathrm{p}}}\right)\right\}$.

The Bellman-Zadeh approach to multiobjective decision making has the advantage of requiring only an ordinal evaluation of the preference information, but it has also the disadvantage of not allowing one to include the fact that the objective differ in importance. For the case that we define a set of different importance $\{P\}=\left\{b_{1}, b_{2}, b_{3}, \ldots . b_{p}\right\}$, the overall decision function $D$ takes a more general form:

$\mathrm{D}=\mathrm{M}\left(\mathrm{A}_{1}, \mathrm{~b}_{1}\right) \cap \mathrm{M}\left(\mathrm{A}_{2}, \mathrm{~b}_{2}\right) \cap \mathrm{M}\left(\mathrm{A}_{3}, \mathrm{~b}_{3}\right) \ldots \ldots \cap \mathrm{M}\left(\mathrm{A}_{\mathrm{p}}, \mathrm{b}_{\mathrm{p}}\right)$,

where $M\left(A_{i}, b_{i}\right)$ is a new function involving objective $A_{i}$ and its importance $b_{i}$. Yager $(1977,1978)$ extended the Bellman-Zadeh approach in order to include the importance of the various objectives(preferences), using Saaty theory, (Saaty, 1975;1977), who has developed a procedure for obtaining a ratio scale for group of elements, based upon a paired comparison of each of the elements. Yager (1977) applied the above method of Saaty, assigning to each objective a power indicative of its importance and then raising each fuzzy set to its appropriate power. These powers were obtained by getting the eigenvector of the maximum eigenvalue of a matrix of paired comparisons of the objectives and the overall decision function $\mathrm{D}$ takes the form:

$D=A_{1}^{\alpha_{1}} \cap A_{2}^{\alpha_{2}} \cap A_{3}^{\alpha_{3}} \ldots \ldots \cap A_{p}^{\alpha_{p}}$,

and the corresponding membership function $\mu_{\mathrm{D}}$ :

$\mu_{\mathrm{D}}=\operatorname{Min}\left(\mu_{\mathrm{A}_{1}}{ }^{\alpha}, \mu_{\mathrm{A}_{2}}{ }^{\alpha}, \mu_{\mathrm{A}_{3}}{ }^{\alpha_{3}}, \ldots \ldots . . \mu_{\mathrm{A}_{\mathrm{p}}}{ }^{\alpha} \mathrm{p}\right)$.

As he notes (Yager, 1981) in some cases it may be very difficult for a decision maker to supply information about $\alpha_{i}$ and he extended his methodology, applying the logical implication:

$\mathrm{b}_{\mathrm{i}} \rightarrow \mathrm{A}_{\mathrm{i}}=\neg \mathrm{b}_{\mathrm{i}} \vee \mathrm{A}_{\mathrm{i}}=\mathrm{b}_{\mathrm{i}}^{\prime} \vee \mathrm{A}_{\mathrm{i}}, \quad \neg \mathrm{b}_{\mathrm{i}}=\mathrm{b}_{\mathrm{i}}^{\prime}=1-\mathrm{b}_{\mathrm{i}}$

and showing that $A_{i}^{b_{i}}$ and $b_{i}^{\prime} \vee A_{i}$ are both acceptable operations for implication, that is, they both generally act in the same manner. Now the decision function $D$ becomes:

$\mathrm{D}=\bigcap_{\mathrm{i}=1}^{\mathrm{p}}\left(\mathrm{b}_{\mathrm{i}}^{\prime} \cup \mathrm{A}_{\mathrm{i}}\right)$.

The maximum of the new function $D$ becomes:

$\operatorname{Max}\left\{\mu_{\mathrm{D}}\right\}=\operatorname{Max}\left\{\min \left\{\mu_{\mathrm{C}_{1}}, \mu_{\mathrm{C}_{2}}, \mu_{\mathrm{C}_{3}}, \ldots \ldots \mu_{\mathrm{C}_{\mathrm{p}}}\right\}\right\}$,

where $C_{i}=\left(1-b_{i}\right) \cup A_{i}$. 


\section{APPLICATIONS}

\subsection{Application area}

The Néstos River flows in south western Bulgaria and western Thrace, Greece (Mylopoulos et al., 2004). The Néstos rises on Kolarov peak of the Rila Mountains of the north western Rhodope (Rodopi) Mountains. The river's upper confluents separate the Rila and Pirin ranges from the main Rhodope massif. Crossing the Bulgarian frontier into Greece, the Néstos divides Greek Macedonia from Greek Thrace. About $110 \mathrm{~km}$ of the river flow through Bulgaria and about $130 \mathrm{~km}$ through Greece. The total catchment's area of the river is about $5800 \mathrm{~km}^{2}$, of which $\sim 2800 \mathrm{~km}^{2}(48 \%)$ belong to Greece. From just west of Stavroúpolis to its mouth on the Aegean Sea, 150 miles (240 $\mathrm{km}$ ) from its source, it forms the boundary between Kaválla and Xánthi departments. Above Paranéstion, however, the river is confined to inaccessible gorges, as it traverses the sparsely populated, mountainous Dráma department. West of Xánthi , Néstos reaches the marshy, alluvial coastal plain of Chrysopolis.

The area mainly consists of metamorphic rocks and marbles (it is believed that in the past they constituted limestone reefs), while the river bed is composed of sedimentary rocks and alluvial deposits (recent fluvial deposits). The Nestos River threads through a large gorge displaying steep rocky slopes and riverside vegetation encompassing well formed clumps of trees and stands of Salix alba, S. fragilis, S. amplexicaulis, S. eleagnos, Populus alba, Pinus nigra. The local habitat also exhibits a sparse growth (individuals) of Platanus orientalis and Alnus glutinosa. From a geological point of view, the area belongs to the Rodopi mass. The climatic type ranges between the Mediterranean and continental type of climate.

Mpaka (2006), applying compromise programming, studied and suggested the construction of five dams (five alternatives, $X_{1}=A B, X_{2}=A D, X_{3}=A R, X_{4}=B A$, and $X_{5}=M A$ )) with their corresponding reservoirs in Néstos watershed (Fig. 1): 1) The dam of Agia Barbara (AB), 2) The dam of Ano Potamaki (AD), 3) The dam of Arkoudorema (AR), 4) The dam of Bathyrema (BA) and 5)The dam of Mavrorema. (MA)

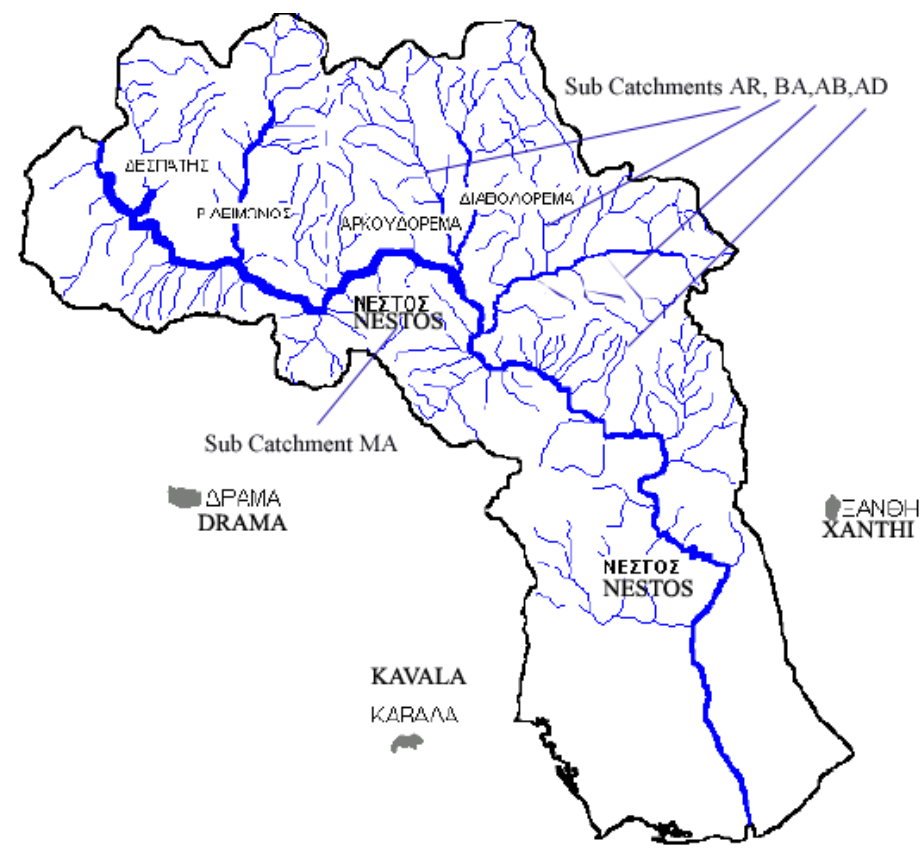

Figure 1. Néstos Catchment area.

\subsection{Results}

The research concerning the five sub catchments focused in an estimation of the cost of each dam $(€)$, the volume $\left(\mathrm{m}^{3}\right)$ and the area $\left(\mathrm{m}^{2}\right)$ of the reservoir, and the potential hydroelectric power (in $\mathrm{kW}$ ) (Mpaka, 2006). The decision maker has to define four objectives $\left(A_{1}, A_{2}, A_{3}, A_{4}\right)$ (Table 1), that impact the decision: a) The small cost of the dam $\left(A_{1}\right)$, b) the environmental impact of each dam $\left.\left(A_{2}\right), c\right)$ the produced hydroelectric power $\left(A_{3}\right)$, and d) the protection of floods $\left(A_{4}\right)$. Besides one also decides to rank the preferences for these objectives on the unit interval $\left(b_{1}, b_{2}, b_{3}, b_{4}\right)$. 
Hence one sets up the problem as follows: a) $X=\{A B, A D, A R, B A, M A\}=\left\{X_{1}, X_{2}, X_{3}, X_{4}, X_{5}\right\}$, b) $A$ $=\{$ cost, env, power, flood $\left.\}=\left(A_{1}, A_{2}, A_{3}, A_{4}\right), c\right) P=\left\{b_{1}, b_{2}, b_{3}, b_{4}\right\}$.

Table 1. Objectives for each dam

\begin{tabular}{cccccc}
\hline a/a & AB & AP & AR & BA & MA \\
\hline Cost & 0.286 & 0.169 & 0.197 & 0.122 & 0.225 \\
\hline Env & 0.171 & 0.180 & 0.321 & 0.265 & 0.063 \\
\hline Power & 0.126 & 0.116 & 0.328 & 0.358 & 0.071 \\
\hline Flood & 0.131 & 0.160 & 0.319 & 0.328 & 0.063
\end{tabular}

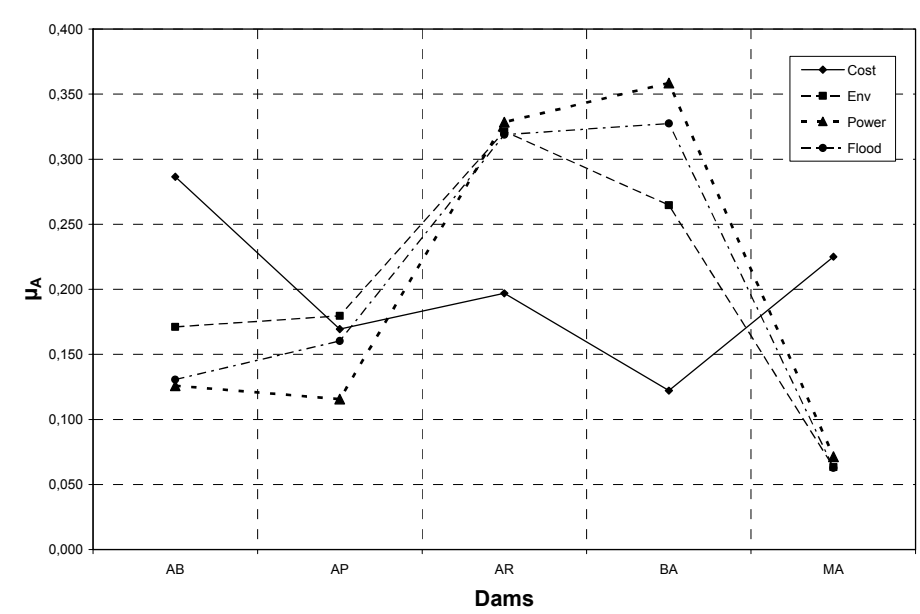

Figure 2. Memberships for each alternative with respect to the objectives

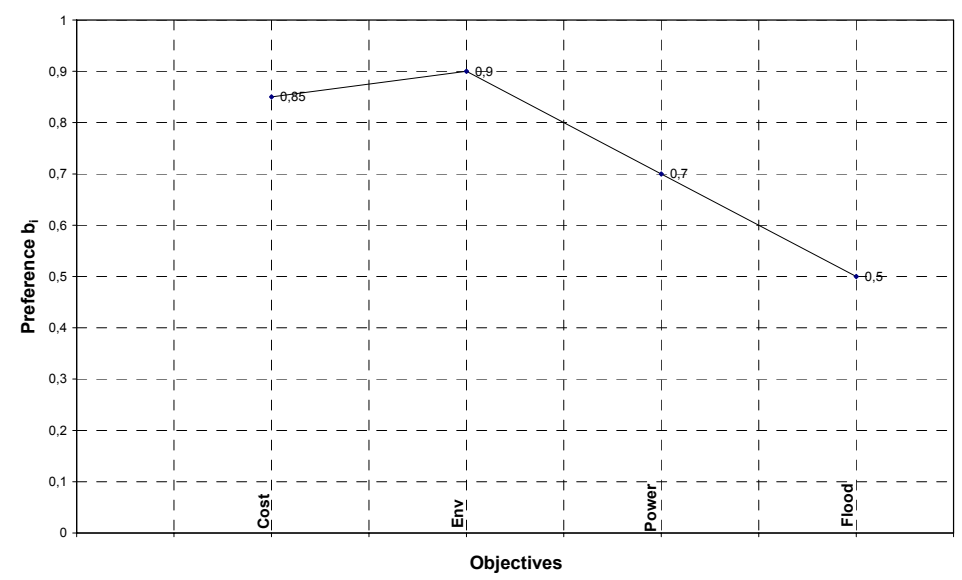

Figure 3. Importance of each objective

The ratings of the dams with respect to the objectives are given here expressed in Zadeh's notation (Zadeh, 1965, 1973):

$$
\begin{aligned}
& \tilde{\mathrm{A}}_{1}=\left\{\frac{0.286}{\mathrm{AB}}+\frac{0.169}{\mathrm{AR}}+\frac{0.197}{\mathrm{BA}}+\frac{0.122}{\mathrm{BA}}+\frac{0.225}{\mathrm{MA}}\right\} \\
& \tilde{\mathrm{A}}_{2}=\left\{\frac{0.171}{\mathrm{AB}}+\frac{0.180}{\mathrm{AR}}+\frac{0.321}{\mathrm{BA}}+\frac{0.265}{\mathrm{BA}}+\frac{0.063}{\mathrm{MA}}\right\} \\
& \tilde{\mathrm{A}}_{3}=\left\{\frac{0.126}{\mathrm{AB}}+\frac{0.116}{\mathrm{AR}}+\frac{0.328}{\mathrm{BA}}+\frac{0.358}{\mathrm{BA}}+\frac{0.071}{\mathrm{MA}}\right\} \\
& \tilde{\mathrm{A}}_{4}=\left\{\frac{0.131}{\mathrm{AB}}+\frac{0.160}{\mathrm{AR}}+\frac{0.319}{\mathrm{BA}}+\frac{0.328}{\mathrm{BA}}+\frac{0.063}{\mathrm{MA}}\right\}
\end{aligned}
$$


Now, one wishes to determine the sensitivity of the optimum solution to the preference ratings.(The preference ratings were defined subjectively, Ross, 2004). From these preferences (Fig. 3) the following calculations result:

$$
\begin{aligned}
& b_{1}=0.85, \quad b_{2}=0.9, \quad b_{3}=0.7, \quad b_{4}=0.5 \\
& b_{1}^{\prime}=0.15, \quad b_{2}^{\prime}=0.1, \quad b_{3}^{\prime}=0.3, \quad b_{4}^{\prime}=0.5 \\
& \mu_{\tilde{D}\left(X_{1}\right)}=\left(b_{1}^{\prime} \cup \tilde{A}_{1}\right) \cap\left(b_{2}^{\prime} \cup \tilde{A}_{2}\right) \cap\left(b_{3}^{\prime} \cup \tilde{A}_{3}\right) \cap\left(b_{4}^{\prime} \cup \tilde{A}_{4}\right) \\
& =(0.15 \vee 0.286) \wedge(0.10 \vee 0.171) \wedge(0.3 \vee 0.126) \wedge(0.5 \vee 0.131)= \\
& =0.286 \wedge 0.171 \wedge 0.3 \wedge 0.5=0.171 \\
& \mu_{\tilde{D}\left(X_{2}\right)}=\left(b_{1}^{\prime} \cup \tilde{A}_{1}\right) \cap\left(b_{2}^{\prime} \cup \tilde{A}_{2}\right) \cap\left(b_{3}^{\prime} \cup \tilde{A}_{3}\right) \cap\left(b_{4}^{\prime} \cup \tilde{A}_{4}\right) \\
& =(0.15 \vee 0.169) \wedge(0.10 \vee 0.180) \wedge(0.3 \vee 0.116) \wedge(0.5 \vee 0.160)= \\
& =0.169 \wedge 0.180 \wedge 0.3 \wedge 0.5=0.169 \\
& \mu_{\tilde{D}\left(X_{3}\right)}=\left(b_{1}^{\prime} \cup \tilde{A}_{1}\right) \cap\left(b_{2}^{\prime} \cup \tilde{A}_{2}\right) \cap\left(b_{3}^{\prime} \cup \tilde{A}_{3}\right) \cap\left(b_{4}^{\prime} \cup \tilde{A}_{4}\right) \\
& =(0.15 \vee 0.197) \wedge(0.10 \vee 0.321) \wedge(0.3 \vee 0.328) \wedge(0.5 \vee 0.319)= \\
& =0.197 \wedge 0.321 \wedge 0.328 \wedge 0.5=0.197 \\
& \mu_{\tilde{\mathrm{D}}\left(\mathrm{X}_{4}\right)}=\left(\mathrm{b}_{1}^{\prime} \cup \tilde{\mathrm{A}}_{1}\right) \cap\left(\mathrm{b}_{2}^{\prime} \cup \tilde{\mathrm{A}}_{2}\right) \cap\left(\mathrm{b}_{3}^{\prime} \cup \tilde{\mathrm{A}}_{3}\right) \cap\left(\mathrm{b}_{4}^{\prime} \cup \tilde{\mathrm{A}}_{4}\right) \\
& =(0.15 \vee 0.122) \wedge(0.10 \vee 0.265) \wedge(0.3 \vee 0.358) \wedge(0.5 \vee 0.328)= \\
& =0.150 \wedge 0.265 \wedge 0.358 \wedge 0.5=0.150 \\
& \mu_{\tilde{\mathrm{D}}\left(\mathrm{X}_{5}\right)}=\left(\mathrm{b}_{1}^{\prime} \cup \tilde{\mathrm{A}}_{1}\right) \cap\left(\mathrm{b}_{2}^{\prime} \cup \tilde{\mathrm{A}}_{2}\right) \cap\left(\mathrm{b}_{3}^{\prime} \cup \tilde{\mathrm{A}}_{3}\right) \cap\left(\mathrm{b}_{4}^{\prime} \cup \tilde{\mathrm{A}}_{4}\right) \\
& =(0.15 \vee 0.225) \wedge(0.10 \vee 0.063) \wedge(0.3 \vee 0.071) \wedge(0.5 \vee 0.063)= \\
& =0.225 \wedge 0.100 \wedge 0.3 \wedge 0.5=0.100 \\
& \operatorname{Max}\left\{\mu_{\tilde{D}}\right\}=\operatorname{Max}\left\{\mu_{\tilde{D}\left(X_{1}\right)}, \mu_{\tilde{D}\left(X_{2}\right)}, \mu_{\tilde{D}\left(X_{3}\right)}, \mu_{\tilde{D}\left(X_{4}\right)}, \mu_{\tilde{D}\left(X_{5}\right)}\right\}= \\
& =\operatorname{Max}\{0.171,0.169,0.197,150,100\}=0.197
\end{aligned}
$$

Consequently one chooses the third alternative, which means the dam of Arkoudorema.

\section{CONCLUSIONS}

A problem of multiobjective decision making in water resources management has been presented here, in the catchment area, of Néstos having five alternatives (five dams) to consider for selecting the optimum solution. Applying the Yager (1981) methodology, one concluded that the best solution is the dam of Arkoudorema with the following criteria:The cost of the dam 0,197, $\left.\left(b_{1}=0.85\right), b\right)$ the environmental impact of the dam $\left.0.321,\left(b_{2}=0.90\right), c\right)$ the produced hydroelectric power 0.328 , $\left(b_{3}=0.70\right)$, and $\left.d\right)$ the protection of floods $0.319,\left(b_{4}=0.50\right)$. This method is very easy for engineering applications and one can proceed, making simple numerical calculations. But as is pointed out Ross (2004), the objectives and the preferences are not known with precision and are rather subjective. Much of this imprecision is not measurable or random and it can be due to vague, ambiguous, or fuzzy information. According to Carlson and Fuller (1996), decision making in practice has shown that fuzzy logic allows decision making with estimated values in spite of incomplete information and even if a decision may not be correct, it can be improved later when additional information is available. It is also possible in the above problem to have a different set of importance and the decision maker will then choose an other best solution. 


\section{REFERENCES}

Belmann R. and Zadeh L. (1970), Decision making in a Fuzzy Environment, Management Sciences, 17(4), B141-164.

Belton V. and Stewart T. (2001), Multiple criteria decision analysis, Springer US, pp. 372.

Carlsson C. and Fuller R. (1996), Fuzzy multiple criteria decision making. Recent developments, Fuzzy Sets and Systems, 78, 139-153.

Cox E. (2007), Fuzzy Modelling and Genetic Algorithms for Data Mining and Exploration, Morgan Kaufmann Publishers, San Francisco, USA, pp. 530.

Duckstein L., Bobée B. and Ashkar F. (1991), A Multiple Criteria Decision Modelling approach to selection of estimation techniques for fitting extreme floods, Stochastic Hydrol. Hydraul., 5, 227-238.

Iliadis L. (2007), Intelligent information systems and application in risk estimation, A. Stamouli, Thessaloniki-Greece(in Greek), pp. 248

Iliadis L. and Maris F. (2007), An Artificial Neural Network model for mountainous water-resources management: The case of Cyprus mountainous watersheds, Env. Modelling \& Software, 22(7), 10661072.

Kecman V. (2001), Learning and Soft Computing, the MIT Press, Cambridge, MA, USA, pp. 608.

Mpaka M. (2006), Compromise programming. Application in the case of Nestos catchment's area, MS thesis, Aristotle University of Thessaloniki-Department of Surveying and Rural Engineering. Thessaloniki.Greece

Mylopoulos Y., Kolokytha E. and Vagiona D. (2004), Transboundary Water Management in Nestos River. The European "Iron Curtain" Project, Protection and Restoration of the Environment VII., 1-8. Mykonos. Greece.

Ross T. (2004), Fuzzy Logic with Engineering Applications, John Wiley \& Sons Ltd, England, pp. 628.

Roy B. (1968), Classement et choix en présence de points de vue multiples (la méthode ELECTRE), la Revue d'Informatique et de Recherche Opérationelle (RIRO), 8, 57-75.

Saaty T.L. (1975), Hierarchies and priorities-eigenvalue analysis, unpublished Working Paper, University of Pennsylvania.

Saaty T.L. (1977), A scaling method for priorities in hierarchical structures, Journal of Mathematical Psychology, 15, 234-281.

Saaty T.L. (1980), The analytic hierarcy process, New York, McGraw-Hill.

Yager R. and Basson D. (1975), Decision making with Fuzzy Sets, Decision Sciences, 6, 590-600.

Yager R. (1977), Multiobjective Decision using Fuzzy Sets, Decision Sciences, Int. J. Man-Machine Studies, 9, 375-382.

Yager R. (1978), Fuzzy Decision making including unequal objectives, Fuzzy Sets and Systems, 1, 8795.

Yager R. (1981), Concepts, Theory, and Techniques. A new Methodology for Ordinal Multiobjective Decisions based on Fuzzy Sets, Decision Sciences, 12, 589-600.

Zadeh L.A. (1965), Fuzzy sets, Information and Control, 8, 338-353.

Zadeh L.A. (1973), Outline of a new Approach to the Analysis of Complex Systems and Decision Processes, IEEE ans. on Systems,Man, amd Cybernetics, Vol. SMC-3, No. 1, January 1973.

Zeleny M., (1982), Multiple criteria decision making, McGraw-Hill Book Co. N.Y., pp.563.

Zimmermann H.-J. (1992), Methods and Applications of Fuzzy Mathematical Programming in "An Introduction to Fuzzy Logig Applications in Intelligent Systems" by Yager R. and Zadeh L., Kluwer Academic Publishers, pp. 97-120.

Zimmermann H.-J. (1996), Fuzzy set Theory, Kluwer Academic Publishers, Boston/Dordrecht/London. pp.435. 